\title{
EMOTIONAL STATUS OF PATIENTS IN CANCER: A CASE REPORT
}

'ÇAKMAK S, ${ }^{2}$ AŞIK ÖZDEMIR V

${ }^{1}$ Karadeniz Technical University Faculty of Health Sciences, Internal Medicine Nursing Department Trabzon, Turkey. ${ }^{2}$ Recep Tayyip Erdoğan University High School of Health, Internal Medicine Nursing Department, Rize, Turkey.

Introduction: Cancer patients have to cope with many physical problems during the disease process. Patient experience many feelings like hopelessness, loneliness, anxiety, stress, fear of death in complex form. Therefore, maintaining the spiritual balance of the patient is an important part of the care process.

Objectives: The nurse is the primary external support for cancer patients as a care provider. For this reason, it is the responsibility of the nurse to improve the complex emotional state of the patient.

Methods: The study was performed with a 51-year-old female patient with breast malignant neoplasm. In the preliminary practice of the study, face-toface interview technique was applied to determine the strengths and weaknesses of the patient in the process and the disability was assessed. The questionnaire including open-ended, semi-structured questions was administered to the patient and the emotional state was assessed. A nursing care plan was prepared and applied according to the Roy Adaptation Theory appropriate to the patient's condition in the data obtained from the questionnaire results.

Results: The data obtained at the end of the questionnaire showed that the patient was not sufficient in the fight against cancer and needed emotional support. There were feelings of hopelessness, frustration and weakness in the patient. Particularly, the patient's sense of hope has been improved at the end of the aimed nursing care process.

Conclusions: According to the result obtained from the study, it is very important to determine and support not only physical but also emotional needs of cancer patients in disease process.

Key Words: cancer, emotional status, nursing care

III- According to Roy's Adaption Model, Nursing Care Plan for Problems Regarding Role Function Field

Behaviour: She says that it is difficult to do housework and she couldn't take care of her children as before.

Focus stimulus: Cancer diagnosis

Affecting stimulus: Being hospitalized, fatigue, weakness

Possible stimulus: She is afraid of falling while doing housework.

Nursing diagnosis: Unability to fulfill her roles

Objective: To ensure her to do her roles with the current situation

Nursing Initiatives:

- She are told to refrain from activities that force her.

- The times when her energy is high are determined and activities that can be done are planned.

- The patient's family members are interviewed and they are told to give support to the patient

- It is explained that the treatment process causes her to feel tired and to be temporary.

Evaluation: She feels hopeful about she fulfills her roles as before

IV. According to Roy's Adaptation model, Nursing Care Plan for the Problems Regarding to Mutual Loyalty Field

Behaviour: After her illness, she feels frustrated that very close friends don't call her and ask get away.

Focus stimulus: Cancer diagnosis

Affecting stimulus: Deterioration in social relations

Possible stimulus: She thinks if she can not beat the disease, her relationship with her friends will be end.

Nursing diagnosis: Loneliness risk

Objective: Not feeling loneliness

Nursing Initiatives:

- She is encouraged to share her feelings and to express her fears.

- The patient is checked more frequently and is not allowed to remain alone.

Evaluation:

- The patient G.A. stated that she hoped to heal someday and that her social relationships would improve.

- She expressed that if she is patient, she will be close to God.

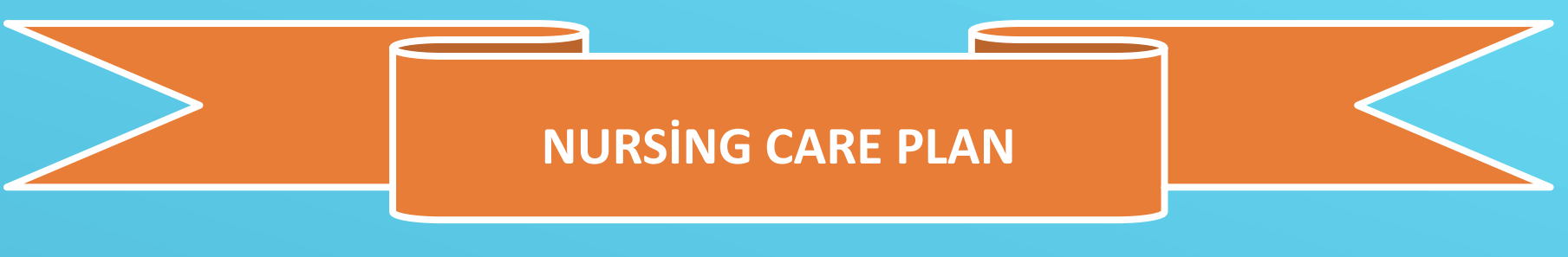

I- According to Roy's Adaptation Model, Nursing Care Plan for Problems Regarding the Physiological Field

Behaviour: Patient needs help for daily needs.

Focus stimulus: Cancer diagnosis

Affecting stimulus: Chemotherapy

Possible stimulus: She avoids moving

Nursing diagnosis: Fatigue

Objective: Paricipate in stimulant and balancing activities as emotional, physical, social and cognitive of the patient

Nursing Initiatives

- The patient is asked to record her activity state and the hourly fatigue state within days.

- Findings are evaluated together.

- The most tired and the most dynamic feelings are revealed.

- Energetic feelings are supported. In these period, activities for self are provided.

- Visitor planning is done one by one by everyone. Information about effective coping methods (relaxation, speech, communicate...) is given.

Evaluation: Observed to have an increase in patient G.A.'s activity.

II-According to Roy's Adaptation Model, Nursing Care Plan for Problems Regarding the Ego/Ego Field

Behaviour: The flickering of her voice during the talking, the filling of her eyes Focus stimulus: Not knowing what the health condition will be.

Affecting stimulus: Change in health status

Possible stimulus: The thought that she will not heal and her children will be alone.

Nursing diagnosis: Anxiety

Objective: The patient's anxiety control, physiological and psychological relaxation.

Nursing Initiatives:

- A quiet, secure communication environment is provided. Anxiety statements are monitored and recorded. Anxiety level of patient and family is determined.

- The way the patient copes with anxiety is followed.

- The treatment and initiatives are explained to the patient and her family.

- At the appropriate time, information is provided on the patient's condition, treatment and care in cooperation with the physician.

Evaluation

- The patient G.A. was said to be a positive contribution to the healing of treatment and to be patient.

- The patient expresseed her comfort.

Behaviour: She express that her greatest fear is to be in need of others

Focus stimulus: Cancer diagnosis

Affecting stimulus: Hospitalization, difficulty in doing daily work.

Possible stimulus: She thinks she got breast cancer because she didn't breasfeed her children.

Nursing diagnosis: Fear

Objective: Facing and overcoming fear.

Nursing Initiatives:

- It is an opportunity to express her fair openly.

- How to deal with their fear is determined.

- Cooperation with family members is provided and support is provided.

Evaluation: Mrs. G.A. stated that she was hopeful in the future.

Ursavaş FE, Karayurt Ö, İşeri Ö (2014). Nursing approach based on Roy Adaptation Model in a patient undergoing breast conserving surgery for breast cancer. The journal of breast health 10(3): 134.

Zhu L, Schroevers MJ, Lee M, Garssen B, Stewart RE, Sanderman R, Ranchor AV (2015). Trajectories of personal control in cancer patients receiving psychological care. Psycho-Oncology 24(5): 556-563. 